\title{
Study on Intestinal Helminth Parasites in School Children of Rangeli Municipality of Morang District in Eastern Nepal
}

\author{
Shiva Narayan Yadav ${ }^{1}$, Sanjay Mahato, ${ }^{1, \text {, * }}$ \\ ${ }^{1}$ Mahendra Morang Adarsh Multiple Campus, Department of Zoology and Microbiology, Tribhuvan University, Biratnagar, Nepal \\ ${ }^{2}$ Aasra Research and Education Academy Counsel, Biratnagar, Nepal
}

Email address:

yadav_s67@yahoo.com (S. N. Yadav), mahato.sanjay@gmail.com (S. Mahato)

${ }^{*}$ Corresponding author

\section{To cite this article:}

Shiva Narayan Yadav, Sanjay Mahato. Study on Intestinal Helminth Parasites in School Children of Rangeli Municipality of Morang District in Eastern Nepal. American Journal of Health Research. Vol. 5, No. 2, 2017, pp. 50-53. doi: 10.11648/j.ajhr.20170502.15

Received: January 24, 2017; Accepted: February 21, 2017; Published: March 9, 2017

\begin{abstract}
This study was accomplished on school children with the objective to define the prevalence of intestinal helminth parasites. A total of 3000 of stool samples were randomly collected from children of five schools in Rangeli municipality and were examined by a routine by saline and smear techniques. $83.3 \%$ stool samples were infected with helminth parasites. The prevalence rate of intestinal parasites was Ascaris lumbricoides (50.92\%); Ancylostoma duodenale (44.56\%); Trichuris trichiura (1.96\%); Enterobius vermicularis (1.44\%); Hymenolepis nana (1.12\%). The lack of safe drinking water, food, poverty, unhygienic practices and poor environmental condition were found to be contributing factors in the maintenance of high prevalence rate of intestinal parasites infections. Parasites control programs with hygienic practice and improvement of environmental conditions along with the treatment of infected peoples may be helpful in reducing the burden of helminth intestinal parasites in children. Hygienic conditions benefit people at personal and community level and, ultimately contributes to promoting the health status of people.
\end{abstract}

Keywords: Helminthiasis, Prevalence Rate, Stool Samples, Rangeli-Morang District, Eastern Nepal

\section{Introduction}

Intestinal parasites infections are common in the world responsible for considerable morbidity and mortality [1-3]. As of now people earning less than two US dollars per day in developing regions of Asia, sub-Saharan Africa, North America and South America are mostly infected with one or more helminth [4]. It is estimated that approximately 2 billion people are infected with soil-transmitted helminths worldwide. More than 880 million children need treatment for these helminthic parasites [5]. While comparing all the age group, school-aged children, and preschool children be likely to harbor the largest numbers of helminth and the reasons for it is not well understood. Because of such condition, children develop growth stunting, impaired memory and cognition [6]. Around 450 million school children are clinically infected with intestinal parasitic infection [7]. The world has 800-1000 million cases of Ascaris, 700 to 900 million cases of hookworm infections and 500 millions of Trichuriasis [8]. Intestinal parasitic infections are estimated to infect roughly $50 \%$ of children and adolescents nationwide [9]. The common mode of transmission of the gastro-intestinal infections is faecal-oral. Infection is more frequently in younger children in the urban areas [7].

The poor environment, unsafe human waste disposable system, lack of safe water supply, and poverty have contributed to the main causes of a high prevalence of intestinal parasitic infections [10]. Climate and topography determine the distribution of helminth infections while heterogeneity of the same helminth is an epidemiological occurrence [11, 12]. Soil-transmitted helminths are highly affected by soil type and surface temperature along with altitude and rainfall $[13,14]$. Evidence of clustered housing of infected people exists for ascariasis and trichuriasis [15].

The average intensity of infection of Ascaris lumbricoides and Trichuris trichiura rises in children aged 5-15 years and declines in intensity and frequency in adulthood [16] while hookworm often displays a firm rise in the intensity of 
infection with age which peaks up in adulthood [17].

Only a few drugs - albendazole, oxamniquine, praziquantel, ivermectin, together with diethylcarbamazine and mebendazole - are developed to treat the most common disease in the world "helminthiases" $[18,19]$.

In Nepal, very few studies are available only covering few focus areas. Keeping all these in mind, the present study is helpful to control measures for the prevalence of intestinal parasitosis and suitable for the eradication of parasitic infection throughout the country covering school students of urban and rural areas. Many workers have studied the helminth parasitic infections of human [2027].

\section{Study Area}

Takuwa, Battarbari and Kasijan area under Rangeli Municipality of Morang district in eastern Nepal was selected as study area. It lies in the Koshi zone. At primary schools of Takuwa and Battarbari, a total of 3000 children of 5-10 years of age from a poor socio-economic status with low levels of nutrition were studied.

\section{Materials and Methods}

This study was conducted during January to June 2016. A total of 3000 stool samples were randomly collected from children of 3 primary schools covering Rangeli municipality and were examined.

Direct smear method technique was employed for the stool examination. A saline preparation was done and few drops of saline $(0.9 \%)$ was taken on a slide and a match head of fecal material by means of the disposable applicator was taken on saline water. The stool samples were mixed with saline and placed on the slide with a cover slip and were observed under a microscope.

\section{Result}

Over the 6 months from January to June 2016, a total of 3000 samples were studied among school children from different primary schools of Rangeli municipality in Morang district of eastern Nepal. Out of 3000 samples, 2500 (83.3\%) fecal samples were infected with helminth parasites. Among the specific helminth parasites, infection is shown in the Table 1 .

Table 1. Prevalence percent of specific intestinal helminth parasites.

\begin{tabular}{llll}
\hline S. N. & Helminth Parasites & Number of Samples Infected & Percentage \\
\hline 1 & Ascaris lumbricoides & 1273 & $50.92 \%$ \\
2 & Ancylostoma duodenale & 1114 & $44.56 \%$ \\
3 & Trichuris trichiura & 49 & $1.96 \%$ \\
4 & Enterobius vermicularis & 36 & $1.44 \%$ \\
5 & Hymenolepis nana & 28 & $1.12 \%$ \\
\hline
\end{tabular}

Out of 2500 infected; 1368 (54.72\%) samples were of male children and 1132 (45.28\%) samples were of female children.

Table 2. Species wise infestations with different parasites in male children.

\begin{tabular}{llll}
\hline S. N. & Helminth Parasites & Number of Samples Infected & Percentage \\
\hline 1 & Ascaris lumbricoides & 681 & $49.78 \%$ \\
2 & Ancylostoma duodenale & 605 & $44.22 \%$ \\
3 & Trichuris trichiura & 37 & $2.7 \%$ \\
4 & Enterobius vermicularis & 26 & $1.9 \%$ \\
5 & Hymenolepis nana & 19 & $1.39 \%$ \\
\hline
\end{tabular}

Table 3. Species wise infestations with different parasites in female children.

\begin{tabular}{llll}
\hline S. N. & Helminth Parasites & Number of Samples Infected & Percentage \\
\hline 1 & Ascaris lumbricoides & 582 & $51.41 \%$ \\
2 & Ancylostoma duodenale & 504 & $44.52 \%$ \\
3 & Trichuris trichiura & 23 & $2.03 \%$ \\
4 & Enterobius vermicularis & 14 & $1.24 \%$ \\
5 & Hymenolepis nana & 9 & $0.8 \%$ \\
\hline
\end{tabular}

The prevalence rate of total infections was higher in males $(54.72 \%)$ as compared to females $(45.28 \%)$. Thus, with respect to sex, in the case of the prevalence rate of infestations with helminth parasites in male was higher $(54.72 \%)$ than females $(45.28 \%)$. Helminth infection and gender were found to be independent of each other with $\chi_{\text {stat }}^{2}$ $(5.164)<\chi_{\text {crit }}^{2}(9.488)$ at $\mathrm{p}=0.05$ and $\mathrm{df}=4$.

\section{Discussion}

This study was carried out to find the present prevalence of intestinal helminth parasites among the school going children. Of all the stool samples from school children, five different type of helminth intestinal parasites were found where Ascaris lumbricoides (Roundworm) was most prevalent than the Ancylostoma duodenale. Trichuris trichiura, Enterobius vermicularis (pinworm) and Hymenolepis nana showed very low prevalence rate.

The outcome in present study differed from previous studies, which revealed that the total prevalence of parasitic infection was higher in percentage compared to infection reported with the findings of Nepal and Palfy (1980), 
Upadhyay (1981), Cutts and Quinlisk (1980), Gupta (1987) Gupta and Gupta (1998), Parajuli, et al. (2001), Rai, et al (1993), Vaidya and Acharya (1998), Sherchand et al (1998), Rijal et al (2001). Analysis of the Tribhuvan University Teaching Hospital record from 1985 - 1992 revealed that the prevalence rates of the intestinal parasites were 29.1 to $43 \%$ and the higher prevalence was found in children [28]. The high prevalence rate in this study might be due to poor socioeconomic condition, climatic and environmental conditions of the area, a poor personal hygienic condition which could be more favorable for intestinal parasites, along with unsafe water supply, contamination of food, soil and vegetables and sanitation facilities [29]. This high prevalence rate of parasites infection is prevailing health problem of the country.

\section{Conclusion}

The high rate of parasitic infections of the gastro-intestinal tract may account for a high proportion of death in infants with low hygiene and nutrition. This study has observed that the lack of sanitation knowledge and hygienic practice among school going children and poverty were the main cause. Consequently, there has been a need for parasitic control program with wide participation from local NGOs and community for the control of helminth parasite infections. Soil-transmitted helminths weaken the infected and sometimes cause death. Such infections decrease school performance. Sometimes surgical intervention is needed when intestinal obstruction and rectal prolapse occur. Since $83.33 \%$ of the student population in the school is infected with these parasites, such area needs a bi-annual treatment as per WHO recommendation. Along with antihelminthics, people at risk should be educated for improvement in sanitation and health education as control measures.

\section{References}

[1] World Health Organization (WHO). Basic Laboratory Method in Medical Parasitology. 1991.

[2] Haque R. Human intestinal parasites. J Health Popul Nutr. 2007; 25: 387-91.

[3] Abah A. E., Arene F. O. I. Status of Intestinal Parasitic Infections among Primary School Children in Rivers State, Nigeria. Journal of Parasitology Research 2015. Volume 2015, Article ID 937096.

[4] Hotez P. J., et al. Control of neglected tropical diseases. N. Engl. J. Med. 2007, 357: 1018-1027.

[5] WHO (2012). Research Priorities for Helminth Infections: technical report of the TDR disease reference group on helminth infections. Technical report series; no. 972. WHO Press, Geneva.

[6] Hotez P. J. et al. "Helminth infections: the great neglected tropical diseases", Journal of Clinical Investigation, 2008. 118(4): 1311-1321.

[7] Tiwari BR et. al. Prevalence of Intestinal Parasitic Infections among School Children of Dadeldhura District. Nepal JHAS, 2013. Vol. 3, No. 1, P 14-16.

[8] Abate A. et al. Cross-Sectional Study on the Prevalence of Intestinal Parasites and Associated Risk Factors in Teda Health Centre, Northwest Ethiopia. ISRN Parasitology, 2013. Volume 2013, Article ID 757451.

[9] WHO Country Cooperation Strategy Nepal, 2013-2017. 2013. ISBN 978-92-9022-428-0.

[10] Mara D. et al. Sanitation and Health. PLoS Med. 2010. 7(11): doi: 10.1371 .

[11] Greenland K. et al. The Epidemiology of Soil-Transmitted Helminths in Bihar State, India. PLoS Negl Trop Dis, 2015. 9 (5): e0003790.

[12] Brooker S. et al. Spatial heterogeneity of parasite co-infection: Determinants and geostatistical prediction at regional scales. IJP, 2008. Volume 39 (5) 591-597.

[13] Debalke S. et al. Soil Transmitted Helminths and Associated Factors Among Schoolchildren in Government and Private Primary School in Jimma Town, Southwest Ethiopia. Ethiop J Health Sci. 2013; 23(3): 237-244.

[14] Tchuente L. A. Control of soil-transmitted helminths in subSaharan Africa: Diagnosis, drug efficacy concerns and challenges. Acta Tropica, 2010. 120S (2011) S4-S11.

[15] Walker M., Hall A., Basanez MG. Individual Predisposition, Household Clustering and Risk Factors for Human Infection with Ascaris lumbricoides: New Epidemiological Insights. New Epidemiological Insights. PLoS Negl Trop, 2011. Dis 5 (4): e1047.

[16] Rujeni N., Taylor DW., Mutapi F. Human Schistosome Infection and Allergic Sensitisation. Journal of Parasitology Research, 2012. Vol.2012, pp. 1-17., 10.1155/2012/154743.

[17] Weatherhead J. E., Hotez P. J. Worm Infections in Children. Pediatrics in review, 2015. Vol. 36 No. 8.

[18] Hotez P. J. Forgotten people and forgotten diseases, the neglected tropical diseases and their impact on global health and development. ASM Press. 2008.

[19] Chirac P., Torreele E. Global framework on essential health R\&D. Lancet. 2006; 367: 1560-1561.

[20] Sah R. B. et al. A study of prevalence of intestinal parasites and associated risk factors among the school children of Itahari, Eastern Region of Nepal. Tropical parasitology, 2013. 3 (2): 140-144.

[21] Pradhan P. et al. Prevalence of intestinal parasitic infections among public school children in a rural village of Kathmandu Valley. Nepal Med Coll J 2014; 16 (1): 50-53.

[22] Shrestha A, KC Narayan, Sharma R. Prevalence of Intestinal Parasitosis among School Children in Baglung District of Western Nepal. Kathmandu Univ Med J 2012; 37 (1): 3-6.

[23] G Regmi P., et al. Prevalence of Intestinal Parasites and Associated Risk Factors among School Children of Kalaiya in Bara District, Nepal. JSM Microbiology, 2014. 2 (1): 1009.

[24] Rijal et al. Gender Variation in the Prevalence of Parasites infection and the level of Awareness in Adolescent in rural Nepal. South East Asian J. Trop. Med. Public Health, 2001. 32 (3), $575-580$. 
[25] Khadka KS et. al. Study of Intestinal Parasitosis among School Going children in Pokhara, Nepal. JHAS, 2013, Vol. 3, No. 1 P 47-50.

[26] Singh GK et al. The prevalence of intestinal parasitic infestation in a tertiary care hospital - a retrospective study. Journal of Nobel Med Coll., 2013. Vol. 2 (1) Issue 3.

[27] Sherchand G. A cross-sectional study on Intestinal Parasites infection in Primary School children of Godar VDC Nepal. J. Nep. Assoc. for medical laboratory Sc., 1998. 1:61-62.
[28] Rai SK et al. Status intestinal parasitosis at Maharajgunj Teaching Hospital (T. U.). J. Inst. Med. Nep., 1995. 17: 134142 .

[29] Iman F. Abou-El-Naga. Demographic, socioeconomic and environmental changes affecting circulation of neglected tropical diseases in Egypt. Asian Pacific Journal of Tropical Medicine, 2015. 8 (11): 881-888. 